\title{
Are learning skills associated with academic emotions elicited by master's thesis work?
}

Hintsanen, M. ${ }^{\mathrm{a}}$ and Pyhältö, K. ${ }^{\mathrm{a}, \mathrm{b}}$

${ }^{a}$ Faculty of Educational Sciences, University of Oulu, Oulu, Finland.

${ }^{b}$ Faculty of Educational Sciences, University of Helsinki, Helsinki, Finland.

\section{Author Information}

Mirka Hintsanen (corresponding author):

Faculty of Educational Sciences, University of Oulu, Oulu, Finland, and Institute of Behavioural Sciences, University of Helsinki, Helsinki, Finland.

Postal address: Faculty of Education, P.O. Box 2000 (Yliopistokatu 9), 90014 University of Oulu, Oulu, Finland. Phone: +358 - 50569 5243. E-mail: mirka.hintsanen@oulu.fi

Kirsi Pyhältö:

Faculty of Educational Sciences, University of Oulu, Oulu, Finland, and Institute of Behavioural Sciences, University of Helsinki, Helsinki, Finland.

Postal address: Faculty of Education, P.O. Box 2000 (Yliopistokatu 9), 90014 University of Oulu, Oulu, Finland. Phone: +358 - 50413 6147. E-mail: kirsi.pyhalto@oulu.fi

Abstract word count: 151

Manuscript word count: 5132

\section{Notes on contributors}

Mirka Hintsanen is Professor of Psychology at University of Oulu, Finland.

Kirsi Pyhältö is Professor of Educational Sciences at University of Oulu and Research Director at University of Helsinki, Finland. 


\begin{abstract}
Examining academic emotions in the context of master's thesis work is a highly understudied issue. This study examined association of self-regulated learning skills and academic emotions elicited by master's thesis work. Altogether 84 behavioural sciences students conducting their master's theses completed a survey comprised of a modified version of Pintrich's Motivated Strategies for Learning questionnaire and academic emotions derived from Pekrun's Achievement Emotions Questionnaire complemented by enthusiasm. Linear and logistic regressions were employed in the data analyses. Higher skills in combining prior and new knowledge, application of theories, self-assessment and the combination of all learning skills were associated with higher positive academic emotions. Higher skills in self-assessment were associated with lower negative academic emotions. Higher combined learning skills were associated with higher pride and enthusiasm and lower shame elicited by master's thesis work. Supporting students to develop their self-regulated learning skills might reflect positively on their academic emotions and vice versa.
\end{abstract}

Keywords: academic emotions; self-regulated learning skills; master's thesis; higher education; undergraduate studies 


\section{Introduction}

Academic emotions are central ingredients in learning. They are shown to have impacts on student cognitive performance, motivation, achievement and decision-making and problem-solving (Damasio 1994, Hannula 2012, Lewis et al. 2011, Linnenbrink-Garcia, Rogat, and Koskey 2011). In general, positive emotions have been associated with good academic performance (e.g. Trigwell, Ellis, and Han 2012), while negative deactivating emotions such as boredom are suggested to be detrimental for learning (Goetz et al. 2014). It has also been suggested that self-regulated learning may enhance positive emotions (Anttila et al. 2016, Saariaho et al. 2016). However, we still know surprisingly little about the relations between self-regulated learning (SRL) skills and academic emotions. Furthermore, academic emotions have rarely been examined in the context of conducting a master's thesis.

\section{Academic Emotions}

The expression academic emotions, refers to a set of emotions experienced during academic activities, typically in studying, learning and following teaching (Pekrun et al. 2002). They are intense, short-lived affective states that arise in response to particular stimuli (e.g. Do and Schallert 2004). Academic emotions are socially constructed and personally enacted. They may be process related, i.e. arising during the studying or learning process (activity emotions), or they may emerge as an outcome of judgements of perceived success in attaining a goal or in maintaining one's standards (outcome emotions) (Anttila et al. 2016, Pekrun 2006, Pekrun et al. 2002, Schutz et al. 2006). They are dependent both on the context and the task at hand (Averill 1980, Schutz et al. 2006).

Prior studies within the area of academic emotions have focused on how and why the emotions emerge, their role in shaping student engagement and achievement, and student regulation of emotional resources (Linnenbrink-Garcia and Pekrun 2011). The focus has been especially on 
test-related emotions, primarily test anxiety (e.g. Mandler and Sarason 1952, Stough and Emmer 1998). Other emotions like, pride, shame, hope and fear have been largely ignored in field studies on studying and learning (Pekrun et al. 2002), although in recent years interest in these emotions has increased greatly (Linnenbrink-Garcia and Pekrun 2011).

Academic emotions are often explored in the valence-arousal framework, the valence referring to the positive or negative tone of the emotion, and the arousal to whether the experience is activating, neutral or deactivating (Barrett and Russell 1998, Kleine et al. 2005). The valence of enjoyment, hope and pride is positive, whereas anxiety, anger and boredom are typically perceived as negative (Goetz et al. 2007). Arousal, in turn (i.e. Pekrun et al. 2002), is unipolar and refers to mobilization and energy, i.e. to the intensity of the emotional reaction (Barrett and Russell 1998, Kleine et al. 2005). Enjoyment and anger, for example, are perceived as highly activating (Kleine et al. 2005), whereas relief and boredom are suggested to be deactivating because they reduce tension and have a low arousal level (Kleine et al. 2005). Furthermore, some emotions, such as happiness and sadness, are referred to as neutral and not particularly activating or deactivating (Linnenbrink 2007).

In general, positive emotions have been related to positive academic outcomes and high achievement (e.g. Trigwell, Ellis, and Han 2012). Positive emotions, including enjoyment, hope and pride, have been associated, for instance, with the use of more effective learning strategies and academic performance (Ketonen and Lonka 2013, King and Areepattamannil 2014, Trigwell, Ellis, and Han 2012). Moreover, joy, hope and pride have been shown to associate positively with students academic self-efficacy and motivation (Pekrun et al. 2002, Valiente, Swanson, and Eisenberg 2012). In addition, a small-scale qualitative study on student teachers indicated that use of self- and co-regulated learning skills was associated with positive emotions (Saariaho et al. submitted). Positive emotions have also been shown to increase social interaction (Lyubomirsky, King, and Diener 2005), creativity (Fredrickson 2001) and to improve academic achievement 
(Trigwell, Ellis, and Han 2012). In turn, negative deactivating emotions such as boredom are suggested to be detrimental for learning (Goetz et al. 2014, Lewis et al. 2011). Anxiety has, for instance, shown to be related to lower achievement in lecture courses among higher education students (Ketonen and Lonka 2012). Lack of interest on the other hand, has been shown to be a central predictor of student dropout (Goetz et al. 2014, Mäkinen, Olkinuora, and Lonka 2004). Positive emotions do not, however, automatically result in positive learning outcomes or vice versa. For instance, positive deactivating emotions such as relief may hinder performance due to low stimulation level, whereas negative activating emotions may benefit achievement (Pekrun et al. 2002, Rowe, Fitness, and Wood 2015). In summary, academic emotions play a role in several academic outcomes, which emphasizes the importance of examining academic emotions and their antecedents.

According to Pekrun's (Pekrun et al. 2002) control-value theory of academic emotions, academic emotions arise from two factors: First, value appraisals the student places on learning and outcomes of learning and second, control appraisals related to the controllability of learning tasks, which is increased, e.g., by how competent the student feels in the face of the tasks (Pekrun et al. 2002). Also, others have suggested that students' academic emotions are related to their ability to master the task at hand (Delle Fave and Massimini 2005). This ability is likely to be partly dependent on the students' SRL skills.

\section{Self-regulated Learning Skills}

SRL can be suggested as a key for mastering and completing highly demanding and complex tasks (Belski and Belski 2014) such as writing a thesis. SRL is found to predict good academic performance, and is associated with a deep approach to learning (Heikkilä and Lonka 2006), high self-efficacy beliefs (Bandura 1997), intrinsic motivation (Deci, Ryan, and Williams 1996) and better academic achievement (Mega, Ronconi, and De Beni 2014). Interrelation between positive 
emotions and SRL have been detected (Mega, Ronconi, and De Beni 2014, Saariaho et al.

submitted). Positive emotions and positive cognitive appraisals of the learning situation have been, for instance, shown to increase students' SRL and commitment in the learning task (Boekaerts 2011). On the other hand, engagement in SRL is postulated to contribute to higher achievement (Pintrich 2004), which in turn is suggested to produce positive emotions like enjoyment (Pekrun 2006).

Cognitive and metacognitive strategies that are used in regulating the learning and studying process are essential components of SRL (Duncan and McKeachie 2005, Pintrich 2004, Pintrich et al. 1991). Cognitive strategies refer to the strategies student use to master actual learning tasks (e.g. rehearsal, elaboration), whereas metacognitive strategies refer to the strategies students use to plan, control and evaluate their learning process (e.g. setting goals, assessing the level of understanding) (Duncan and McKeachie 2005, Pintrich 2004).

SRL skills can be suggested to reflect control related to the learning tasks and learning processes as effective learning skills enable students to handle the learning tasks and learning process more flexibly. When the student has good SRL skills, he/she has control over the learning tasks and learning process by knowing how to proceed with the tasks and how to effectively perform and organize learning tasks. The ability to assess one's own progress is likely to further contribute to control. According to Pekrun's control-value theory of academic emotions, control appraisals are one major factor affecting academic emotions and the theory further postulates that SRL skills, among other factors, affect academic emotions (Pekrun 2006).

Previous research on SRL skills and academic emotions has shown that in general higher SRL skills are associated with higher positive emotions and lower negative emotions. For instance, a large-scale study on nearly 6000 undergraduates showed that higher skills on elaboration, selfassessment, strategies for studying for an exam, time management and meta-cognition were correlated with higher positive and lower negative study-related academic emotions (Mega, 
Ronconi, and De Beni 2014). Similar results have been found in other studies which have included discrete emotions. Higher SRL skills like elaboration have been found to correlate with higher enjoyment, hope, and pride and lower anger, frustration, anxiety, shame, hopelessness and boredom (Artino and Jones 2012, Cho and Heron 2015, Kim, Park, and Cozart 2014, King and Areepattamannil 2014, Pekrun et al. 2011). All studies have not included the same learning skills or the same set of emotions and also some null findings to some of the emotions have been reported, however, in general, the findings support the above-mentioned associations. It should be noted that some of the previous studies have reported associations between SRL skills and academic emotions as side results and the main focus has been on other issues (Cho and Heron 2015, Kim, Park, and Cozart 2014). Thus, they have not taken into account potential confounders in the relation between SRL skills and emotions.

So far associations between SRL skills and emotions have been examined mostly in the context of studying in general (King and Areepattamannil 2014, Mega, Ronconi, and De Beni 2014, Pekrun et al. 2011) and in the context of online courses (Artino and Jones 2012, Cho and Heron 2015, Kim, Park, and Cozart 2014) or in some cases in relation to some specific subject area (math) (Ahmed et al. 2013). We are not aware of any studies focusing on this issue in the context of conducting a master's thesis. However, examining associations between SRL skills and academic emotions in the thesis writing context may be especially relevant. A master's thesis is a student's most extensive educational task, often setting high demands for a student's SRL skills as the student is, among other tasks, required to search for and combine knowledge from different sources, think independently and critically and to direct the learning and thesis writing process. Thus, associations between SRL skills and academic emotions may be emphasized in the context of thesis work. Furthermore, because of the complexity and long duration of master's thesis work, typically lasting over the whole academic year, the academic emotions that arise during the work are likely to have 
an emphasized importance for enduring motivation and performance. Thus, examining antecedents of academic emotions in the context of a master's thesis is important.

\section{The Current Study}

In this study, we focus on exploring association between SRL skills and academic emotions embedded in the master thesis work among behavioural sciences master's students. We examine seven SRL skills that are based on Pintrich's theory of self-regulated learning (Pintrich and de Groot 1990, Pintrich et al. 1993): Rehearsal (rehearsing, e.g. rereading learning materials), critical thinking (considering accuracy and reliability of information), finding essential points (conducting overviews of the learning materials and assessing what is more and what is less important), connecting prior and new knowledge (connecting knowledge from different sources and linking acquired knowledge with prior knowledge and experiences), key words and advance organizers (finding an outline and using key concepts), application of theories (connecting theoretical knowledge with practice), self-assessment which could also be called elaboration (monitoring one's learning, e.g. by checking understanding) (Niemi, Nevgi, and Virtanen 2003). We examine positive and negative academic emotions and a set of discrete emotions that have been shown to be especially relevant in the studying and learning context (Pekrun et al. 2002). We adjust for the student's age, major subject, and phase of master's thesis which may act as confounders. Drawing from theoretical postulates and previous empirical findings, we hypothesize that higher SRL skills are associated with higher positive emotion and lower negative emotion and that the associations with discrete emotions follow the same pattern (higher SRL skills associating with higher positive discrete emotions and lower negative discrete emotions). 


\section{Methods}

\section{Participants}

The participants were university students from a Finnish university. All students $(n=1317)$ of one department were contacted in 2013 via e-mail, and 262 (20\% of the invited) students responded to the online questionnaire. The current study focuses on those students who were conducting their master's thesis at the time of the data collection $(n=96)$. The final sample $(n=84)$ consists of students with full information on all study variables. There were 78 women and six men in the final sample. Students had major subjects in educational sciences $(n=39)$, psychology $(n=28)$, cognitive sciences $(n=1)$, or speech sciences $(n=16)$. All participants gave their informed consent for participating in the study.

\section{Measures}

Academic emotions were assessed with eight items, each tapping a discrete emotion in the master's thesis context. The emotions were derived from Pekrun's Achievement Emotions Questionnaire (Pekrun et al. 2011, Pekrun, Goetz, and Perry 2005). Hope was replaced with enthusiasm which was considered an important emotion in the master's thesis context. The emotions and corresponding items were: Enjoyment - 'I enjoy master's thesis work'; anxiety - 'Master's thesis work evokes anxiety'; boredom - 'Master's thesis work is boring'; anger/hatred - 'I experience anger or hatred related to my master's thesis'; hopelessness - 'I experience feelings of hopelessness related to my master's thesis'; enthusiasm - 'Working on my master's thesis is stimulating'; shame - 'I experience feelings of shame related to my master's thesis'; pride - 'I experience feelings of pride related to my master's thesis'. The participants responded using a five-point scale $(1=$ fully disagree, $5=$ fully agree). Positive affectivity (PA, Cronbach's alpha $(\alpha)=.80)$ was calculated as a mean of three items (enjoyment, enthusiasm, and pride), and negative affectivity (NA, $\alpha=.83$ ) was calculated as a mean of five items (anxiety, boredom, anger/hatred, hopelessness, and shame) based 
on factor analysis, which produced a two-factor solution. Item loadings were comparatively high (for PA $>.50$ and for NA $>.60$ excluding boredom). There were no cross-loadings $(>=.30)$ between the factors except for boredom, which loaded about equally on both factors (-.377 to PA and .403 to NA). Based on its content and slightly stronger loading on NA, it was categorized as NA.

SRL skills $(\alpha=.87)$ were assessed with a modified version (Niemi, Nevgi, and Virtanen 2003) of Pintrich's Motivated Strategies for Learning questionnaire (Duncan and McKeachie 2005, Pintrich et al. 1991). The measure includes seven sub-scales: Rehearsal $(\alpha=.72)$, critical thinking ( $\alpha=.75)$, finding essential points $(\alpha=.64)$, connecting new and old knowledge $(\alpha=.76)$, key words and advance organizers $(\alpha=.34)$, application of theories $(\alpha=.74)$, and self-assessment $(\alpha=.68)$. Each was assessed with three items and a five-point response scale $(1=$ fully disagree, $5=$ fully agree).

Other variables included gender, age, major subject, and phase of master's thesis. Age was self-reported by selecting one of the following categories: $18-20,21-23,24-26,27-29$, and 30 years or older. As the distribution of age was not normal, two groups were formed for the analyses: $18-29$ years $(n=44)$ and 30 years or older $(n=40)$. As there was only one participant with cognitive sciences as their major subject, cognitive sciences and psychology were combined. Phase of master's thesis was assessed with a question including the following response alternatives: 1 'Master's thesis is not yet timely in my studies', 2 - 'I have planned to start on my master's thesis but I have not started working on it yet', 3 - 'I am just in the beginning in working with my master's thesis (e.g. searched or read literature / familiarized myself with master's thesis instructions)', 4 - 'I have just begun writing / analysing the data', 5 - 'I have written quite a lot but analysing the data has not proceeded very far', 6 - 'Analysing the data has proceeded far, but writing has not proceeded very far', 7 - 'Both writing and analysing the data have proceeded far, but are not quite ready', 8 - 'My master's thesis work as a whole is almost ready', 9- 'My master's thesis is finished'. Participants who had selected categories 1, 2, or 9 were excluded, as they were 
not currently in the phase of conducting their thesis. Categories 3 and 4, 5 and 6 , as well as 7 and 8 , were combined as they were somewhat overlapping. Thus, a three-category variable was formed.

\section{Statistical Analyses}

Master's thesis subject and master's thesis phase were dummy-coded for the analyses. No age interactions with SRL skills were found on positive or negative emotions. Thus, the analyses were run for both age groups together. Of the SRL skills 'key words and advance organizers' was not analysed as the reliability of the scale was clearly below the acceptable level $(\alpha=.34)$. Items of this scale were however included in the combined learning skills. The analyses were conducted with linear and logistic regressions. First, associations of SRL skills with a combined score of positive emotions and a combined score of negative emotions as outcomes were analysed with linear regressions so that separate analyses were run for each SRL skill and the combined learning skill score. Second, associations between combined learning skills and discrete emotions were analysed separately for each discrete emotion with logistic regression. Before running the logistic regressions each discrete emotion variable was dichotomized by a median split. This was done because several of these variables had two peaked distributions. For each analysis two regression models were formed so that in the first model, age was included as a control variable and in the second model, age, subject of study, and phase of master's thesis were included as control variables. All analyses were run with SPSS version 22.

\section{Results}

Table 1 presents the characteristics of the study sample. Table 2 presents bivariate correlations between the study variables. Age correlated with higher combined learning skills $(r=.40, \mathrm{p}<0.01)$ and several of its components. Except for rehearsal (which only correlated with combined learning skills), correlations between different SRL skills varied from medium to large ( $r>.44$ for all). Combined learning skills and several of its components correlated with higher positive emotions (r 
$=.25, \mathrm{p}<.05)$ and lower negative emotions $(\mathrm{r}=-.29, \mathrm{p}<.01)$. Positive and negative emotions correlated negatively with each other $(r=-.66, \mathrm{p}<.01)$.

Insert Tables 1 and 2 about here.

Table 3 presents results of linear regression analyses of associations of SRL skills with positive and negative emotions. Connecting newer and older knowledge $(\beta=.246, p=.033)$, application of theories $(\beta=.249, \mathrm{p}=.037)$, self-assessment $(\beta=.343, \mathrm{p}=.003)$, and combined learning skills $(\beta=.284, \mathrm{p}=.018)$ were associated with higher positive emotions in the ageadjusted model. Only self-assessment $(\beta=-.276, \mathrm{p}=.015)$ was associated with lower negative emotions. These associations remained significant when subject of study and phase of master's thesis were additionally adjusted for ${ }^{1}$.

Insert Table 3 about here.

Table 4 presents results of logistic regression analyses of associations of combined SRL skills with discrete emotions. Of discrete positive emotions, combined learning skills were associated with higher odds for pride $(\mathrm{OR}=2.71, \mathrm{p}=0.034)$ in the age-adjusted model. Association with enthusiasm did not quite reach the level of significance $(p=0.070)$. Of discrete negative emotions, combined learning skills were associated with lower odds for shame $(\mathrm{OR}=0.30, \mathrm{p}=$ 0.014) in the age-adjusted model. The associations for pride and shame remained significant in the fully adjusted model and the association for enthusiasm also became significant so that higher SRL skills were associated with higher odds for enthusiasm $(\mathrm{OR}=2.79, \mathrm{p}=0.47)^{2}$.

Insert Table 4 about here. 


\section{Discussion}

SRL skills were associated especially with positive emotions elicited by master's thesis work. More specifically, higher skills in combining newer and older knowledge, application of theories, selfassessment and the combination of all learning skills were associated with higher positive emotions. In contrast, lower skills only in self-assessment were associated with negative emotions. Of the discrete emotions, higher combined learning skills were associated with higher pride and enthusiasm and lower shame.

Our findings give support to Pekrun's Control-Value Theory of Achievement Emotions that assumes (reciprocal) associations between academic emotions and learning skills (Pekrun 2006). The findings are also in line with earlier research on SRL skills and academic emotions, although it should be noted that no previous study has examined this association in the context of master's thesis writing. Previous studies have included varying sets of SRL skills and academic emotions and used a variety of measures for assessing them, which impedes comparing our results to earlier findings. Despite that, it can be concluded that previous findings are unified in showing a clear direction of higher SRL skills being associated with higher positive emotions and lower negative emotions (Artino and Jones 2012, Cho and Heron 2015, Kim, Park, and Cozart 2014, King and Areepattamannil 2014, Mega, Ronconi, and De Beni 2014, Pekrun et al. 2011), which is in accordance with our findings.

According to Pekrun's theory, academic emotions and SRL skills may have reciprocal association so that emotions affect learning skills and learning skills affect emotions (Pekrun and Stephens 2009). However, longitudinal studies examining temporal relations between academic emotions and SRL skills are rare and accordingly very little evidence on the temporal relations exists, i.e. whether learning skills actually predict academic emotions or vice versa or whether there 
is there the reciprocal association postulated by the theory. A recent study followed 495 secondary school students over a school year examining whether discrete emotions predicted cognitive and metacognitive learning strategies (Ahmed et al. 2013). Of the four examined emotions, enjoyment and pride increased the use of cognitive and metacognitive strategies, whereas boredom decreased rehearsal, and anxiety was not related to a change in strategy use. Unfortunately, reverse causation from learning strategies to emotions was not examined. Yet, it can be presumed that the interrelation between SRL skills and academic emotions is mediated by two complementary mechanisms. Firstly, positive academic emotions are likely to enhance use of SRL skills by increasing cognitive flexibility, creativity and positive evaluation of both the situation and one's abilities to cope with the task at hand. Secondly, skilful learning, i.e. use of SRL skills is likely to increase odds for successful task completion that further enhances positive emotional experiences, resulting in a positive cycle (Saariaho et al. submitted). However, longitudinal studies are required to clarify the temporal relations between learning skills and academic emotions.

Self-assessment was the only learning skill that was related to both (higher) positive and (lower) negative emotions and it had the largest effect size of the SRL skills that were associated with positive emotions, explaining about $11 \%$ of the variance in positive emotions, whereas other skills and the combination of all SRL skills explained each about $6-8 \%$ of the variance in positive emotions. Thus, based on our results, self-assessment seems to be the most important learning skill for positive and negative emotions arising in conducting a master's thesis. In this strategy the student monitors his/her learning, e.g. by checking understanding and reflecting on what (s)he has learned, aiming at deep understanding (Niemi, Nevgi, and Virtanen 2003).

We also examined the associations between the combined SRL skills and discrete emotions. Higher learning skills were related to higher enthusiasm and pride and lower shame. It is possible that lower learning skills hinder master's thesis work leading to difficulties and slow progress, which in turn induces shame, whereas higher learning skills might enhance thesis work leading to 
pride and enthusiasm. Or possibly pride and enthusiasm elevate and shame lowers student's ratings of their SRL skills. Longitudinal research would be needed to clarify the mechanisms and temporal direction between SRL skills and academic emotions.

It is notable that in addition to pride and shame, enthusiasm was the only discrete emotion associated with SRL skills. Enthusiasm was the only emotion that was adopted outside of Pekrun's Achievement Emotions Questionnaire (Pekrun et al. 2011, Pekrun, Goetz, and Perry 2005). Our result implies that enthusiasm is an important emotion, at least in the master's thesis context. Enthusiasm might precede high engagement, particularly dedication, in conducting thesis and hence resilience when facing problems. Accordingly, it may be worthwhile to examine enthusiasm also in other contexts.

Although our results do not give information on temporal relations, it may be that improving master's thesis students' SRL skills would also increase their positive emotions and reduce negative emotions. Based on our results and previous literature on SRL skills it can be suggested that students should be supported in developing their SRL skills during their studies and improving learning skills could also be integrated into master's thesis supervision. Students may face challenges in SRL skills during their thesis work (see Baggetun and Wasson 2006) requiring both short- and long-terms goal setting, use of various strategies, change of actions, developing new understandings and reflecting on one's activities. Hence, insufficient SRL skills are likely to be a reason for a lack of progress in master's studies and even attrition, particularly in conducting a master's thesis. Lack of such skills may also be a reason for a more negative study experience that may increase the risk of study burnout. On the other hand, conducting a master's thesis is suggested to provide a potential arena for rehearsing and developing such skills (Saariaho et al. 2016).

Accordingly, it would be advisable to monitor the students' progression with the master's thesis and to give extra support and advice on SRL skills to those whose skills seem inadequate. This requires that students struggling with their thesis work, due to insufficient SRL skills, are identified, and that 
there is a fit between the kinds of support provided and needed. Accordingly, thesis supervisors themselves should be well equipped in supporting their students in learning SRL skills, i.e. in conducting task analysis, in goal setting, use of various strategies, monitoring the effectiveness of those strategies and in reflections on learning for further learning during thesis work. In addition to direct benefits of SRL skills for master's thesis work, this might reduce negative emotions and increase positive motivating emotions. This is important as positive activating emotions like pride and enthusiasm are suggested to have positive consequences for motivation and achievement (Pekrun et al. 2002). Shame, on the other hand, may have negative consequences for studying. For instance, it has been shown that shame is associated with a higher tendency to procrastinate (Fee and Tangney 2000). However, Pekrun et al. (Pekrun et al. 2002) and Pekrun (Pekrun 2006) state that consequences of negative deactivating emotions, like shame, are not always straightforward, as these kinds of emotions can also have positive consequences, e.g. increase extrinsic motivation.

\section{Limitations and Strengths}

In interpreting our findings a few limitations should be taken into account. As the study was crosssectional, conclusions about the temporal direction of the associations cannot be drawn. More advanced SRL skills may increase positive emotions and decrease negative emotions. However, it is also possible that positive emotions promote the use of such skills. In the current study, the participants rated their academic emotions elicited by working on their master's thesis, whereas the assessment of learning skills was not context bound. Thus, it seems less likely that the academic emotions specifically related to master's thesis work would have affected general SRL skills to a great extent. It seems more probable that general SRL skills would affect the emotions elicited in master's thesis work.

Another important limitation is the low response rate which may compromise the generalizability of the results. Further, as the vast majority of the participants were women and only 
very few men were included in the final sample, the results may not be generalized to men. Further studies should be conducted to examine whether similar results can be found in students from other fields of study than educational and behavioural sciences and whether the results can be generalized to other cultures. For example, the ways of supervising master's theses vary between institutions and cultures, which likely places differing demands on student learning skills. This might affect the association between learning skills and emotions related to master's thesis work. A further limitation is related to our measure of discrete emotions. Although our measures of positive and negative effect were based on several items, each discrete emotion was assessed with a single item, which may reduce the reliability of these measures. Thus, analyses on discrete emotions should be interpreted cautiously.

Our study also includes significant strengths. First of all, we examined academic emotions elicited in master's thesis work, which is a highly understudied issue. Very few studies in general have investigated emotions in this context and to our knowledge no other study has examined associations between SRL skills and academic emotions elicited by master's thesis work. Another strength is that instead of focusing only on anxiety or other negative emotions, that have been a more common focus of related research, we included positive and negative emotions, as well as a variety of discrete academic emotions shown to be relevant in the context of studying and learning (Pekrun et al. 2002).

\section{Conclusions}

SRL skills were associated especially with positive emotions elicited in master's thesis work. Selfassessment seems to be the most important learning skill for positive and negative emotions arising when conducting a master's thesis. Supporting students to develop their SRL skills may be reflected positively on their academic emotions and vice versa. Learning skills, academic emotions and their connections are factors that should be taken into account in master's thesis supervision. 


\section{Notes}

${ }^{1}$ We run additional analyses excluding men and the results remained similar although some of the findings attenuated from significant to marginally significant.

${ }^{2}$ We run additional analyses excluding men and the results remained similar although some of the findings attenuated from significant to marginally significant. 


\section{Acknowledgements}

We gratefully acknowledge the contributions of the study participants.

\section{Disclosure statement}

No potential conflict of interest was reported by the authors. 


\section{References}

Ahmed, W., G. van der Werf, H. Kuyper, and A. Minnaert. 2013. "Emotions, Self-Regulated Learning, and Achievement in Mathematics: A Growth Curve Analysis." Journal of Educational Psychology 105 (1):150-161. doi: 10.1037/a0030160.

Anttila, H., K. Pyhältö, T. Soini, and J. Pietarinen. 2016. "How does it feel to become a teacher? Emotions in teacher education." Social Psychology of Education 19 (1):1-23. doi: 10.1007/s11218-016-9335-0.

Artino, A. R., and K. D. Jones. 2012. "Exploring the complex relations between achievement emotions and self-regulated learning behaviors in online learning." Internet and Higher Education 15 (3):170-175. doi: 10.1016/j.iheduc.2012.01.006.

Averill, J. R. 1980. "A constructivist view of emotion." In Emotion: Theory, research, and experience, edited by R. Plutchik and H. Kellerman, 305-339. New York: Academic Press.

Baggetun, R., and B. Wasson. 2006. "Self-regulated learning and open writing." European Journal of Education 41 (3-4):453-472. doi: 10.1111/j.1465-3435.2006.00276.x.

Bandura, Albert. 1997. Self-efficacy: the exercise of control. New York: W.H. Freeman.

Barrett, L. F., and J. A. Russell. 1998. "Independence and bipolarity in the structure of current affect." Journal of Personality and Social Psychology 74 (4):967-984. doi: 10.1037/00223514.74.4.967.

Belski, R., and I. Belski. 2014. "Cultivating student skills in self-regulated learning through evaluation of task complexity." Teaching in Higher Education 19 (5):459-469. doi: $10.1080 / 13562517.2014 .880685$.

Boekaerts, M. 2011. "What have we learned about the social context-student engagement link?" Teachers College Record 113 (2):375-393.

Cho, M. H., and M. L. Heron. 2015. "Self-regulated learning: the role of motivation, emotion, and use of learning strategies in students' learning experiences in a self-paced online mathematics course." Distance Education 36 (1):80-99. doi: 10.1080/01587919.2015.1019963.

Damasio, Antonio R. 1994. Descartes' error : emotion, reason, and the human brain. New York: Putnam.

Deci, E. L., R. M. Ryan, and G. C. Williams. 1996. "Need satisfaction and the self-regulation of learning." Learning and Individual Differences 8 (3):165-183. doi: 10.1016/S10416080(96)90013-8.

Delle Fave, A., and F. Massimini. 2005. "The investigation of optimal experience and apathy Developmental and psychosocial implications." European Psychologist 10 (4):264-274. doi: 10.1027/1016-9040.10.4.264.

Do, S. L., and D. L. Schallert. 2004. "Emotions and classroom talk: Toward a model of the role of affect in students' experiences of classroom discussions." Journal of Educational Psychology 96 (4):619-634. doi: 10.1037/0022-0663.96.4.619.

Duncan, T. G., and W. J. McKeachie. 2005. "The making of the motivated strategies for learning questionnaire." Educational Psychologist 40 (2):117-128. doi: 10.1207/s15326985ep4002_6.

Fee, R. L., and J. P. Tangney. 2000. "Procrastination: A means of avoiding shame or guilt?" Journal of Social Behavior and Personality 15 (5):167-184.

Fredrickson, B. L. 2001. "The role of positive emotions in positive psychology: The broaden-andbuild theory of positive emotions." American Psychologist 56 (3):218-226. doi: 10.1037/0003-066x.56.3.218.

Goetz, T., A. C. Frenzel, N. C. Hall, U. E. Nett, R. Pekrun, and A. A. Lipnevich. 2014. "Types of boredom: An experience sampling approach." Motivation and Emotion 38 (3):401-419. doi: 10.1007/s11031-013-9385-y. 
Goetz, T., A. C. Frenzel, R. Pekrun, N. C. Hall, and O. Ludtke. 2007. "Between- and within-domain relations of students' academic emotions." Journal of Educational Psychology 99 (4):715733. doi: 10.1037/0022-0663.99.4.715.

Hannula, M. S. 2012. "Exploring new dimensions of mathematics-related affect: embodied and social theories." Research in Mathematics Education 14 (2):137-161. doi: 10.1080/14794802.2012.694281.

Heikkilä, A., and K. Lonka. 2006. "Studying in higher education: students' approaches to learning, self-regulation, and cognitive strategies." Studies in Higher Education 31 (1):99-117. doi: $10.1080 / 03075070500392433$.

Ketonen, E., and K. Lonka. 2012. "Do situational academic emotions predict academic outcomes in a lecture course?" Procedia: Social and Behavioral Sciences 69 (24):1901-1910. doi: 10.1016/j.sbspro. 2012.12.144.

Ketonen, E., and K. Lonka. 2013. "How are situational academic emotions related to teacher students' general learning profiles?" In Interaction in Educational Domains, edited by K. Tirri and E. Kuusisto, 103-114. Rotterdam: Sense Publishers.

Kim, C., S. W. Park, and J. Cozart. 2014. "Affective and motivational factors of learning in online mathematics courses." British Journal of Educational Technology 45 (1):171-185. doi: 10.1111/j.1467-8535.2012.01382.x.

King, R. B., and S. Areepattamannil. 2014. "What Students Feel in School Influences the Strategies They Use for Learning: Academic Emotions and Cognitive/Meta-Cognitive Strategies." Journal of Pacific Rim Psychology 8 (1):18-27. doi: 10.1017/prp.2014.3.

Kleine, M., T. Goetz, R. Pekrun, and N. Hall. 2005. "The structure of students' emotions experienced during a mathematical achievement test." Zentralblatt für Didaktik der Mathematik 37 (3):221-225. doi: 10.1007/s11858-005-0012-6.

Lewis, A. D., E. S. Huebner, P. S. Malone, and R. F. Valois. 2011. "Life Satisfaction and Student Engagement in Adolescents." Journal of Youth and Adolescence 40 (3):249-262. doi: 10.1007/s10964-010-9517-6.

Linnenbrink-Garcia, L., and R. Pekrun. 2011. "Students' emotions and academic engagement: Introduction to the special issue." Contemporary Educational Psychology 36 (1):1-3. doi: 10.1016/j.cedpsych.2010.11.004.

Linnenbrink-Garcia, L., T. K. Rogat, and K. L. K. Koskey. 2011. "Affect and engagement during small group instruction." Contemporary Educational Psychology 36 (1):13-24. doi: 10.1016/j.cedpsych.2010.09.001.

Linnenbrink, E. A. 2007. "The role of affect in student learning: A multi-dimensional approach to considering the interaction of affect, motivation, and engagement." In Emotion in education, edited by P. Schutz and R. Pekrun, 107-124. San Diego: Academic Press.

Lyubomirsky, S., L. A. King, and E. Diener. 2005. "The benefits of frequent positive affect: Does happiness lead to success?" Psychological Bulletin 131 (6):803-851. doi: 10.1037/00332909.131.6. 803.

Mandler, G., and S. B. Sarason. 1952. "A Study of Anxiety and Learning." Journal of Abnormal and Social Psychology 47 (2):166-173. doi: 10.1037/h0062855.

Mega, C., L. Ronconi, and R. De Beni. 2014. "What makes a good student? How emotions, selfregulated learning, and motivation contribute to academic achievement." Journal of Educational Psychology 106 (1):121-131. doi: 10.1037/a0033546.

Mäkinen, J., E. Olkinuora, and K. Lonka. 2004. "Students at risk: Students' general study orientations and abandoning/prolonging the course of studies." Higher Education 48 (2):173-188. doi: 10.1023/B:HIGH.0000034312.79289.ab.

Niemi, H., A. Nevgi, and P. Virtanen. 2003. "Towards self-regulation in web-based learning." Journal of Educational Media 28 (1):49-71. doi: 10.1080/1358165032000156437. 
Pekrun, R. 2006. "The control-value theory of achievement emotions: Assumptions, corollaries, and implications for educational research and practice." Educational Psychology Review 18 (4):315-341. doi: 10.1007/s10648-006-9029-9.

Pekrun, R., T. Goetz, A. C. Frenzel, P. Barchfeld, and R. P. Perry. 2011. "Measuring emotions in students' learning and performance: The Achievement Emotions Questionnaire (AEQ)." Contemporary Educational Psychology 36 (1):36-48. doi: 10.1016/j.cedpsych.2010.10.002.

Pekrun, R., T. Goetz, and R. P. Perry. 2005. Achievement Emotions Questionnaire (AEQ). User's manual. Munich: Department of Psychology, University of Munich.

Pekrun, R., T. Goetz, W. Titz, and R. P. Perry. 2002. "Academic emotions in students' selfregulated learning and achievement: A program of qualitative and quantitative research." Educational Psychologist 37 (2):91-105. doi: 10.1207/S15326985ep3702_4.

Pekrun, R., and E. J. Stephens. 2009. "Goals, Emotions, and Emotion Regulation: Perspectives of the Control-Value Theory - Commentary on Tyson, Linnenbrink-Garcia, and Hill." Human Development 52 (6):357-365. doi: 10.1159/000242349.

Pintrich, P. R. 2004. "A conceptual framework for assessing motivation and self-regulated learning in college students." Educational Psychology Review 16 (4):385-407. doi: 10.1007/s10648004-0006-x.

Pintrich, P. R., and E. V. de Groot. 1990. "Motivational and Self-Regulated Learning Components of Classroom Academic-Performance." Journal of Educational Psychology 82 (1):33-40. doi: 10.1037//0022-0663.82.1.33.

Pintrich, P. R., D. A. F. Smith, T. Garcia, and W. J. McKeachie. 1991. A manual for the use of the motivated strategies for learning questionnaire (MSLQ). Ann Arbor, MI: National Center for Research to Improve Postsecondary Teaching and Learning.

Pintrich, P. R., D. A. F. Smith, T. Garcia, and W. J. Mckeachie. 1993. "Reliability and PredictiveValidity of the Motivated Strategies for Learning Questionnaire (MSLQ)." Educational and Psychological Measurement 53 (3):801-813. doi: 10.1177/0013164493053003024.

Rowe, A. D., J. Fitness, and L. N. Wood. 2015. "University student and lecturer perceptions of positive emotions in learning." International Journal of Qualitative Studies in Education 28 (1):1-20. doi: 10.1080/09518398.2013.847506.

Saariaho, E., H. Anttila, A. Toom, T. Soini, J. Pietarinen, and K. Pyhältö. submitted. "Student teachers' emotional landscapes in self- and co-regulated learning." Manuscript submitted for publication.

Saariaho, E., K. Pyhältö, A. Toom, J. Pietarinen, and T. Soini. 2016. "Student teachers' self- and co-regulation of learning during teacher education." Learning: Research and practise 2 (1):44-63. doi: 10.1080/23735082.2015.1081395.

Schutz, P., J. Hong, D. Cross, and J. Osbon. 2006. "Reflections on investigating emotions in educational activity settings." Educational Psychology Review 18 (4):343-360. doi: 10.1007/s10648-006-9030-3.

Stough, L. M., and E. T. Emmer. 1998. "Teachers' emotions and test feedback." International Journal of Qualitative Studies in Education 11 (2):341-361. doi: $10.1080 / 095183998236809$.

Trigwell, K., R. A. Ellis, and F. F. Han. 2012. "Relations between students' approaches to learning, experienced emotions and outcomes of learning." Studies in Higher Education 37 (7):811824. doi: 10.1080/03075079.2010.549220.

Valiente, C., J. Swanson, and N. Eisenberg. 2012. "Linking Students' Emotions and Academic Achievement: When and Why Emotions Matter." Child Development Perspectives 6 (2):129-135. doi: 10.1111/j.1750-8606.2011.00192.x. 
Table 1. Characteristics $(n=84)$.

\begin{tabular}{lllll}
\hline Variables & $\mathrm{n}$ & $\%$ & mean & $\mathrm{sd}$ \\
\hline
\end{tabular}

Gender

$\begin{array}{lll}\text { Women } & 78 & 92.9 \\ \text { Men } & 6 & 7.1\end{array}$

Age

Younger (18-29)

$44 \quad 52.4$

Older (30-)

$40 \quad 47.6$

Major subject

Educational sciences

$39 \quad 46.4$

Psychology or cogn. sciences

$29 \quad 34.5$

Speech sciences

$\begin{array}{ll}16 & 19.0\end{array}$

Phase of master's thesis

$\begin{array}{lcc}\text { Beginning } & 44 & 52.4 \\ \text { In the middle } & 18 & 21.4 \\ \text { Advanced } & 22 & 26.2\end{array}$

Rehearsal

$3.18 \quad 0.88$

Critical thinking

$3.08 \quad 0.94$

Finding essential Points

$3.84 \quad 0.74$

Connecting prior and new knowledge

$\begin{array}{ll}4.23 & 0.59\end{array}$

Application of theories

$3.36 \quad 0.94$

Self-assessment

$3.36 \quad 0.89$

Combined learning skills

$3.55 \quad 0.55$

Positive emotions

$3.48 \quad 0.96$ 
Table 2. Correlations between study variables $(n=84)$.

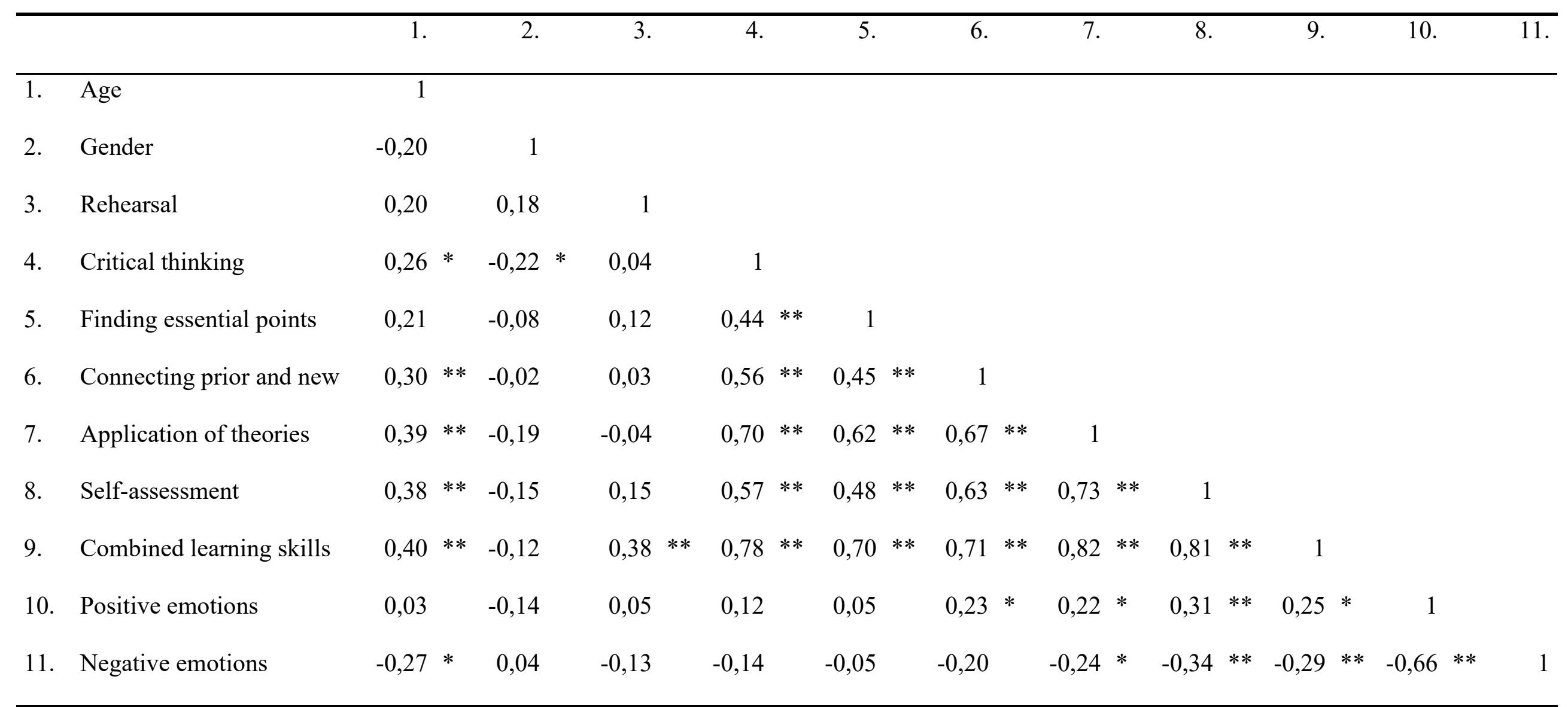

* Correlation is significant at the 0.05 level (2-tailed). $* *$ Correlation is significant at the 0.01 level (2-tailed). Variable coding: gender $(0=$ men,

$1=$ women $)$, age $(0=$ younger, $1=$ older $)$. Connecting prior and new $=$ Connecting prior and new knowledge. 
Table 3. Linear regression analyses on associations of learning skills with positive and negative emotions $(n=84)$.

\begin{tabular}{|c|c|c|c|c|c|c|c|c|c|c|c|c|}
\hline & \multicolumn{6}{|c|}{ Positive emotions } & \multicolumn{6}{|c|}{ Negative emotions } \\
\hline & \multicolumn{3}{|c|}{ Model 1} & \multicolumn{3}{|c|}{ Model 2} & \multicolumn{3}{|c|}{ Model 1} & \multicolumn{3}{|c|}{ Model 2} \\
\hline & & $\overline{R^{\wedge} 2}$ & & & $\overline{\mathrm{R}^{\wedge} 2}$ & & & $\mathrm{R}^{\wedge} 2$ & & & $\overline{\mathrm{R}^{\wedge} 2}$ & \\
\hline & B & change & $\mathrm{p}$ & $\mathrm{B}$ & change & $\mathrm{p}$ & B & change & $\mathrm{p}$ & B & change & $\mathrm{p}$ \\
\hline Rehearsal & .042 & .002 & .714 & .037 & .001 & .753 & _.079 & .006 & .468 & .081 & .006 & .466 \\
\hline Critical thinking & .124 & .014 & .279 & .136 & .016 & .259 & _.072 & .005 & .519 & _.068 & .004 & .553 \\
\hline Finding essential points & .043 & .002 & .704 & .055 & .003 & .653 & .010 & $<.001$ & .928 & .007 & $<.001$ & .951 \\
\hline Connecting prior and new & .246 & .055 & .033 & .255 & .057 & .033 & _.133 & .016 & .233 & _.161 & .023 & .163 \\
\hline Application of theories & .249 & .052 & .037 & .290 & .064 & .024 & _.154 & .020 & .186 & _.159 & .019 & .199 \\
\hline Self-assessment & .343 & .101 & .003 & .363 & .108 & .003 & _.276 & .065 & .015 & $\ldots .280$ & .064 & .017 \\
\hline Combined learning skills & .284 & .068 & .018 & .308 & .075 & .014 & .213 & .038 & .067 & .222 & .039 & .066 \\
\hline
\end{tabular}

Model 1: Adjusted for age. Model 2: Adjusted for age, subject of study, phase of master's thesis. Connecting prior and new $=$

Connecting prior and new knowledge. 
Table 4. Logistic regression analyses on associations of combined learning skills with discrete emotions $(\mathrm{n}=84)$.

$\begin{array}{lllllllll}\text { OR } & 95 \% \mathrm{CI} & \mathrm{p} & \mathrm{OR} & 95 \% \mathrm{CI} & \mathrm{p} & \mathrm{OR} & 95 \% \mathrm{CI} & \mathrm{p}\end{array}$

Positive emotions

\section{Enjoyment}

Enthusiasm

Pride

Model $1 \longdiv { 1 . 8 6 \quad ( 0 . 7 7 ; 4 . 4 8 ) \quad . 1 6 5 }$

$\begin{array}{llllllll}2.45 & (0.93 ; 6.44) & .070 & & 2.71 & (1.08 ; 6.85) & \mathbf{. 0 3 4} \\ 2.79 & (1.02 ; 7.69) & \mathbf{. 0 4 7} & & 3.07 & (1.16 ; 8.13) & \mathbf{. 0 2 4}\end{array}$

Model $2 \quad 1.68 \quad(0.68 ; 4.19) \quad .263$

2.79 $(1.02 ; 7.69)+.047$

Negative emotions

\begin{tabular}{|c|c|c|c|c|c|c|c|c|}
\hline \multirow[b]{2}{*}{ Model 1} & \multicolumn{3}{|c|}{ Anxiety } & \multicolumn{3}{|c|}{ Boredom } & \multicolumn{2}{|r|}{ Hatred / Anger } \\
\hline & 0.85 & $(0.34 ; 2.08)$ & .717 & 1.00 & $(0.42 ; 2.39)$ & .999 & 0.60 & $(0.25 ; 1.47) .267$ \\
\hline \multirow[t]{2}{*}{ Model 2} & 0.79 & $(0.31 ; 1.99)$ & .610 & 1.04 & $(0.42 ; 2.57)$ & .936 & 0.52 & $(0.20 ; 1.34) .175$ \\
\hline & \multicolumn{3}{|c|}{ Hopelessness } & \multicolumn{3}{|c|}{ Shame } & & \\
\hline Model 1 & 0.55 & $(0.22 ; 1.38)$ & .203 & 0.30 & $(0.12 ; 0.78)$ & .014 & & \\
\hline Model 2 & 0.53 & $(0.20 ; 1.40)$ & .203 & 0.33 & $(0.12 ; 0.88)$ & .026 & & \\
\hline
\end{tabular}

Model 1: Adjusted for age. Model 2: Adjusted for age, subject of study, phase of master's thesis. 